\title{
Wireless Multipoint Temperature Detection System Design
}

\author{
HUANG Hui ${ }^{1, a}$, CHEN Debin ${ }^{2, b}$, LU Qingru ${ }^{3, c}$, XIN Haiyan $^{4, d}$ \\ ${ }^{1,2,3,4}$ Department of electronic engineering, Chengxian College, Southeast University, Nanjing \\ Jiangsu 210000, China \\ aemail: huanghui_1225@163.com, bemail: 906720556@qq.com, \\ cemail: silver_1120@163.com, 'email:983511889@qq.com
}

\section{Keywords: Temperature Detector; Wireless Communication; MCU}

\begin{abstract}
In the industrial, agricultural production and daily life, the measurement and control of temperature occupy a very important position. In this paper, it mainly introduces a kind of temperature measurement system which can be collected at multiple points, and the collected data can be transmitted to the host computer through wireless mode. The system can be used in industrial, agricultural and civil multipoint temperature detection.
\end{abstract}

\section{Introduction}

Temperature detection system has broad application prospects. Multipoint temperature measurement system is very important in every field of application, Such as non-destructive detecting temperature of fire fighting, $t$ overheating fault predict detection for telecommunications equipment, temperature detection of the air conditioning system, overheat detection of components of various transportation tools, the application of security monitoring system, medical temperature measurement, chemicals, machinery and other equipment overheated temperature detection. This system design uses the master-slave distributed thought, uses a master computer and multi terminal. The slave computer collects temperature data at each of the temperature measuring points. The temperature results can be transmitted using wireless communications back to the master computer for data processing and display. The slave computer can also work independently, real-time display and control the temperature value of the current points. The system can be used in heavy industrial and civil temperature multi-point monitoring occasions, such as grain storage system, building automation system, temperature control process production line image detection, medical and health, air-conditioning system, petrochemical system, machinery and so on.

\section{System design scheme}

The system uses the distributed design to solve the problem of the traditional temperature measurement system with less temperature measurement point, poor compatibility and poor scalability. It can be used in large scale multi point temperature measurement. The system uses Zigbee communication protocol. This system is mainly made up of master computer (PC), nether machine (MCU)[1][2], temperature control and display module, the sensor of temperature. The master computer (PC) and nether machine (MCU) can transmit messages to each other by Zigbee communication. The nether machine realizes the collection, processing and display of temperature data. The nether machine adopts MCU STC89C52 as the main control chip. System design framework is shown in figure 1. 


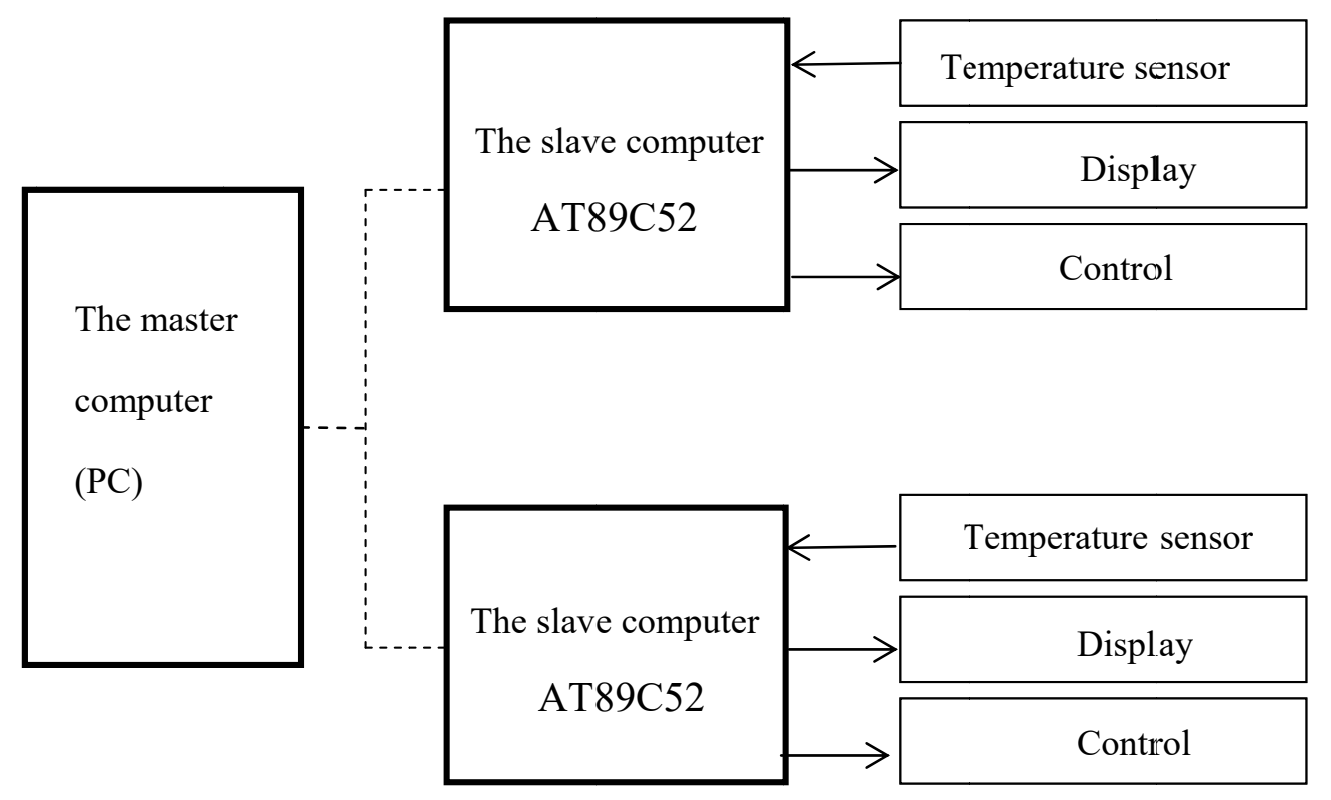

Figure 1 System design framework

\section{Design of the hardware circuit}

\section{Watchdog reset circuit}

By the interference of the surrounding environment, MCU will appear the program running, crash, and some unpredictable abnormal work. Sometimes the staff can't be timely to the scene to restart MCU. So this design adds an external watchdog reset circuit. Circuit diagram is shown in figure 2 .

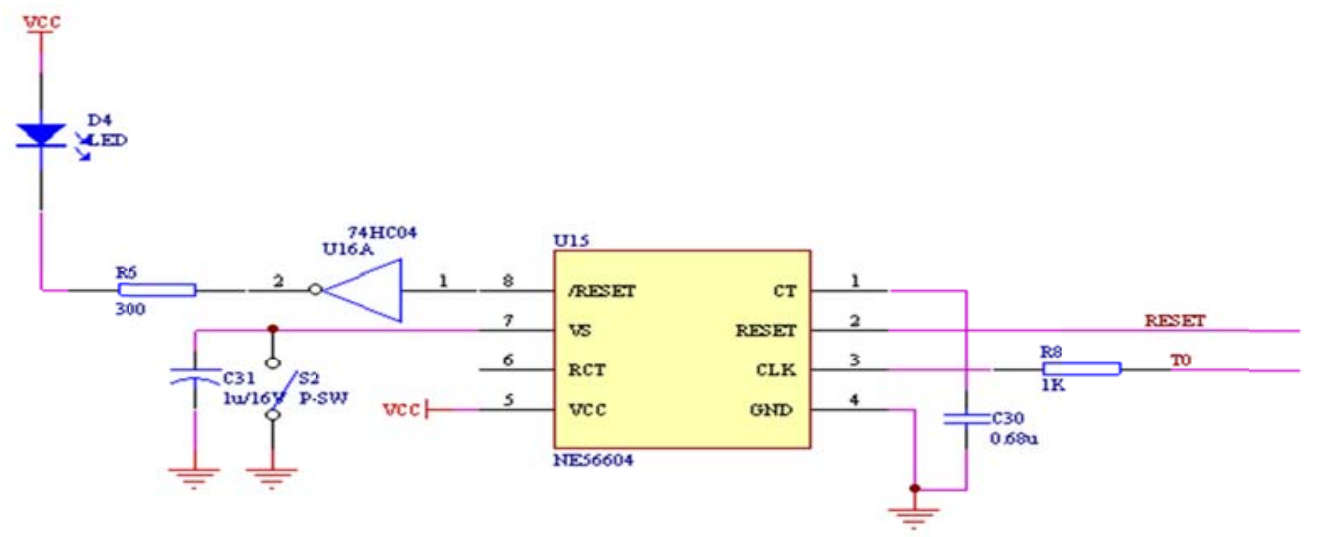

Figure 2 Watchdog reset circuit

In the circuit diagram, the NE56604 is designed to generate a reset signal at a threshold voltage of $4.2 \mathrm{~V}$ for a variety of microprocessor and logic systems. When the power supply is suddenly dropped or the power supply voltage falls below the threshold, the NE56604 will generate a precise reset signal to ensure the normal operation of the microprocessor. NE56604 has a watchdog monitoring time of $100 \mathrm{~ms}$ (typical). 


\section{Temperature sensor circuit}

Temperature sensor of this system is DS18B20[3]. DS18B20 is produced by DALLAS Semiconductor Company. It has the characteristics of small size, low hardware cost, strong anti-interference ability and high precision. Its temperature measurement range is $-55^{\circ} \mathrm{C} \sim+125^{\circ} \mathrm{C}$. In the range of $-10^{\circ} \mathrm{C} \sim+85^{\circ} \mathrm{C}$, its measurement precision is $+0.5^{\circ} \mathrm{C}$. The circuit connection between DS18B20 and MCU is also very simple. As shown in figure 3, its DQ pin is connected to the P1.4 pin of the STC89C52 chip.

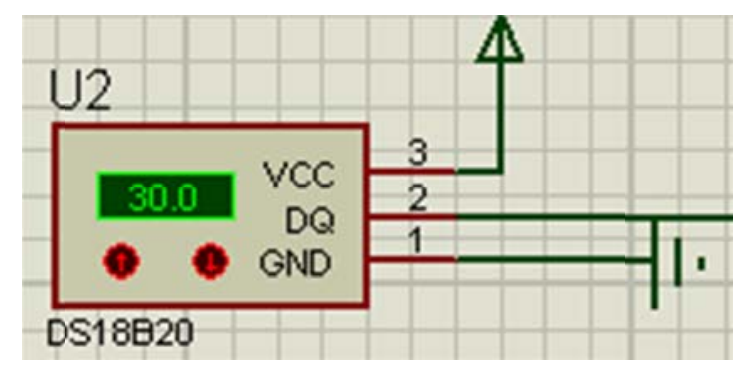

\section{Display circuit}

Figure 3 Temperature sensor circuit diagram

This system is designed using the character type liquid screen display module LCD1602 as the display module. Character type liquid crystal display module is a class specifically for display letters, numbers, symbols, etc., a dot matrix liquid crystal display module, which not only simplifies the hardware design of the system, and greatly improves the reliability of the system. And LCD1602 has low power consumption, long life, small size, display the advantages of rich content, low price, interface control convenient. Therefore, in all kinds of electronic products is most widely popularization and application, the character type liquid crystal display module LCD1602 is used to design the most commonly used information display device. As shown in figure 4, The D0-D7 pin of the LCD1602 is connected to the P0 port of the STC89C52 chip. Controll pin R/W, E, P1.5 are respectively connected to the P1.6, RS, P1.7. Pin 3 is connected to a potentiometer to adjust the contrast so as to achieve the appropriate contrast of the backlight.

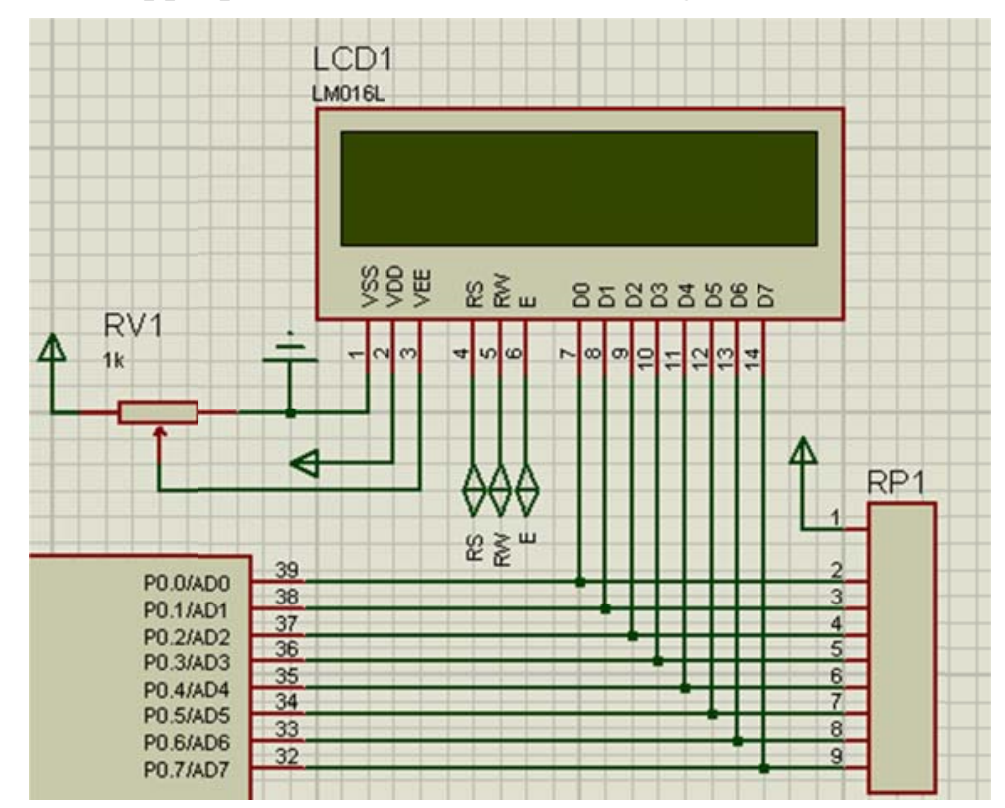

Figure 4 LCD display controlling circuit diagram

\section{Zigbee communication circuit}

Zigbee communication module uses the DL-20 module. This module is embedded with CC2530 chip, can be used to support the use of 51 single-chips. As shown in figure 5, DL-20 wireless 
transmission module has only four pins. The serial communication mode is adopted in the connection with the MCU. Serial data input pin and serial danta output pin can be connected to the pin of MCU serial port pin, as shown in figure 6.

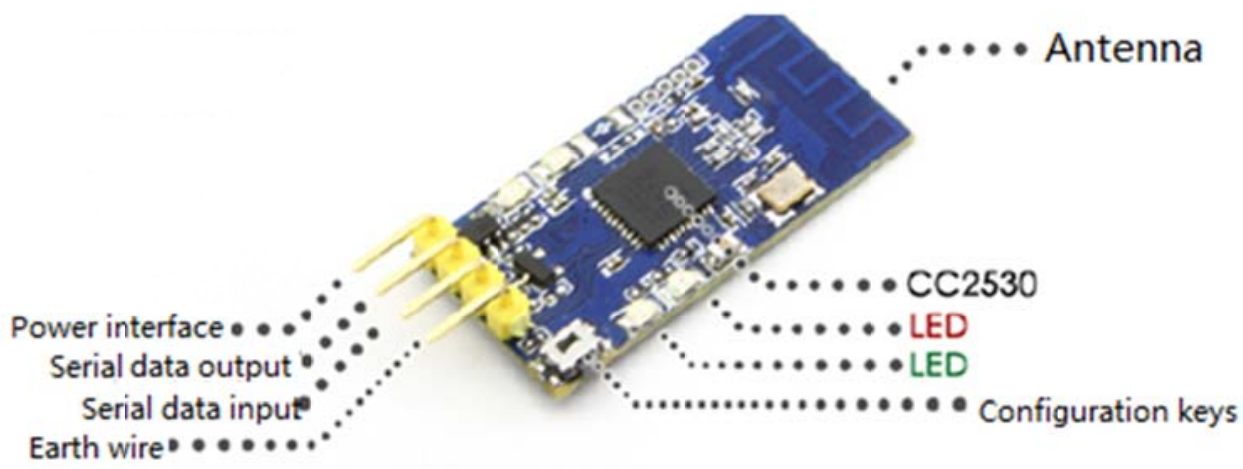

Figure 5 DL-20 Physical map

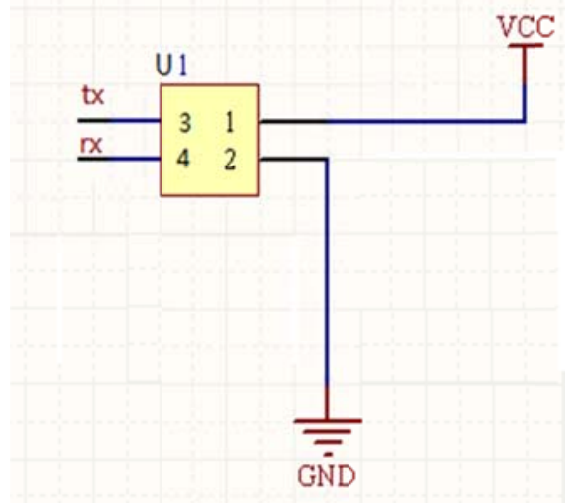

Figure 6 ZigBee connection circuit

\section{Design of the software}

The main program flow chart is shown in figure 7. The main program is first to initialize the system and call for the corresponding subprogram to achieve system function. It mainly includes the subprograms of temperature data gathering and data processing, signal output and Zigbee communication program, LCD display program and so on. Temperature gathering program is to deal with the data sent by the temperature sensor. LCD display program control display part of the system and transfer temperature data to the LCD display. The function of Zigbee communication program is to realize the wireless communication between the master computer and MCU.

The interface of upper computer is carried out under the LabVIEW, and it realizes such functions as the instant display and storage of temperature data of monitor interface, and the handling of measuring results. LabVIEW (Virtual Instrument Engineering Workbench Laboratory) is a program development environment,which developed by the United States National Instrument (NI) Company.[4][5] LabVIEW is using the G graphical programming language editors; the resulting program is block diagram form. LabVIEW Mathematical Library and signal processing library provides a variety of mathematical processing, signal analysis tools, to complete the complex numerical analysis, mathematical calculation and signal processing and other functions. 


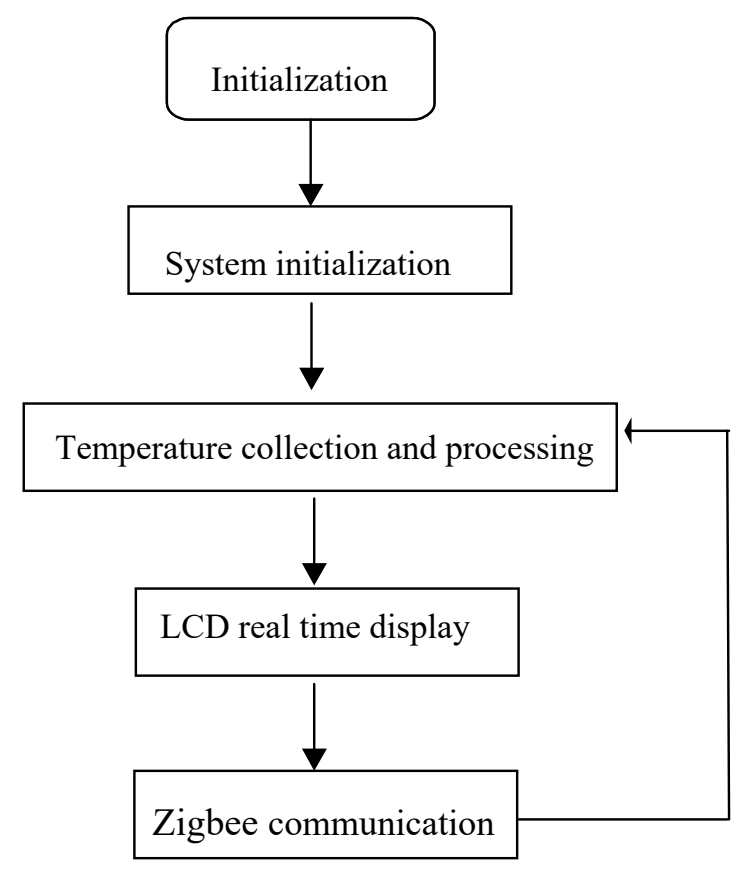

Figure 7 The main program flow chart

\section{Conclusion}

The realization of multi point wireless temperature monitoring system is introduced in this paper. In terms of completion, the hardware and software design of the whole system takes into full consideration of the reliability and validity. The system can perform the scanning of the multipoint temperature, automatic alarm, real-time record, etc. The real time temperature change is monitored by PC based on Zigbee technology. But the monitoring interface of Labview PC can be more perfect. At present, the host computer only completed the display of historical temperature, maximum and minimum values, over temperature alarm, and other simple functions. In the follow-up to improve the process, the system can try to remote control, etc.

\section{References}

[1] Zhang Xin, The Principle and Application of MCU, M.,Electronic Industry Press, 2005:161-258.

[2] Sha Zhanyou, Chinese and Foreign Integrated Sensor Practical Manual, M.,Electronic Industry Press, 2005:200-210.

[3]Zhou Xinpeng, Sensor and Survey Technique, Tsinghua University Press, 2010.9.

[4]Bai Yun, Gao Yupeng, Data acquisition and processing technology based on LabVIEW, Xidian University Press, 2009.

[5]Zhao Jinguang, Research and application of remote measurement based on Labview, Beijing Jiaotong University Press, 2008(6):35-36. 